\title{
Study on Thermal Behaviour and Risk Assessment of Biomass Fuels
}

\author{
Naoharu Murasawa, ${ }^{1, *}$, Hiroshi Koseki ${ }^{2}$, Xin-Rui Li ${ }^{3}$, Yus aku Iwata ${ }^{2}$, Takabumi Sakamoto ${ }^{1}$ \\ ${ }^{1}$ Chiba Institute of Science, Faculty of Risk and Crisis Management, Chiba, Japan \\ ${ }^{2}$ National Research Institute of Fire and Disaster, Toky o, Japan \\ ${ }^{3}$ Texas A\&M University, College Station, Texas, USA
}

\begin{abstract}
Recently, there has been developing of various bio mass fuels because of global warming and rise in the price of crude oil. However, if these biomass fuels are put into practical use without sufficient risk assessment, there is a high risk of accident. From the viewpoint of risk and crisis management, obtaining information about the risk of newly developed biomass fuels is important. For biomass fuels, especially those made from waste, faint heat is generated by fermentation, and this faint heat carries the risk of causing and resulting in spontaneous ignition following an increase in heat temperature. In this study, the risk of faint heat generation by fermentation, which can trigger of spontaneous ignition, has been considered using the sensitive thermal analysis equipment and biomass fuels made from waste, which have been scheduled for future use in Japan. It was found that biomass fuels made from waste generates faint heat by fermentation, such faint heat generation becomes thetrigger of spontaneous ignition.
\end{abstract}

Keywords BiomassFuels, Spontaneous Ignition, Fermentation, Thermal Analysis,RiskAssessment

\section{Introduction}

Japan depends heavily on overseas imports for most of its energy resources, and securing a stable energy has been an important issue here. As the price of crude oil rising and in order to reduce the cost of waste disposal, various biomass fuels has been developing. However, accidents related to biomass fuels, such as fire and explosion, have steadily increased over the years. The accidents related to refuse-derived fuel (RDF) can be considered to be one of the largest biomass fuel-related accidents in Japan[1].

RDF caused spontaneous ignition and explosion in Japan in August 2003, resulting in seven casualties (including two deaths). If a shift to a sustainable society is rushed and new substances are used without full consideration of the safety aspects of handling them, the possibility of occurrence of similar accidents will increase. Domestic power generation from nuclear power has been discontinued as a result of the Great East Japan Earthquake on March 11, 2011, and public support for new methods of power generation has been increasing. Substances produced from waste are expected to be further developed in the future for use as power sources.

Bio mass fuels made from waste have a higher possibility of fermentation. At first a faint heat is generated by

* Corresponding author:

rd10r01@cis.ac.jp (Naoharu Murasawa)

Published online at http://journal.sapub.org/jee

Copyright (C) 2012 Scientific \& Academic Publishing. All Rights Reserved fermentation, then the temperature is assumed to gradually increase. In the case of the heat release cannot dissipate sufficiently, this leads to spontaneous ignition. The wire mesh cube test is an existing assessment method described in the United Nations Recommendations on the Transport of Dangerous Goods[2]. However, this method requires many samples and is time consuming. Furthermore, there is a risk of fire and explosion while performing this method.

This study includes analysis of several kinds of biomass fuels made from waste, all of which are scheduled for future use in Japan, using a combination of sensitive thermal analysis equipment used in the material engineering field, and the risk of faint heat generation due to fermentation, a trigger of spontaneous ignition, was considered for all biomass fuels. Moreover, to prevent fire and explosion during measuring and in order to obtain results in a shorter period of time, a s maller a mount of sample was used.

\section{Experiments}

\subsection{Samples}

The list of biomass fuels used in this study is shown in Table 1. Wood pellets were made from logged trees which were ground and then formed into pellets for use as fuel in wood stoves. Two kinds of pellets were used, pellets from tree bark (Figure. 1) and pellets from tree trunks. Sewage sludge was easily obtained, and its conversion and use as fuel is expected to reduce sewage sludge disposal costs[3]. 
Chicken dung (Figure. 2) was used as fuel for boilers and for heating equipment on chicken farms. Palm shells were obtained from oil palm residue after the manufacturing of soap and cooking oil.

Table 1. List of biomass fuels used in this study

\begin{tabular}{|c|}
\hline Sample names \\
\hline Wood pellets (made from tree bark) \\
\hline Woodpellets (made from tree trunks) \\
\hline Sludge fuel \\
\hline Chicken dung \\
\hline Palm shell fuel \\
\hline
\end{tabular}

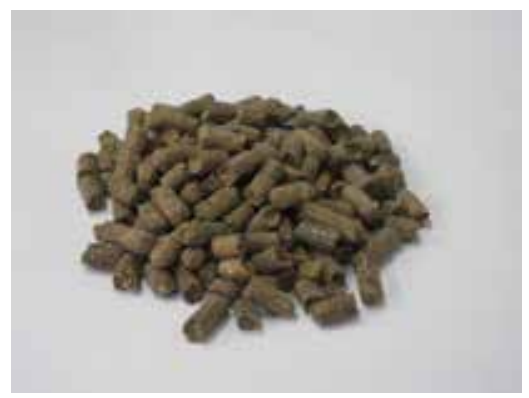

Figure 1. Wood pellets (made from tree bark)

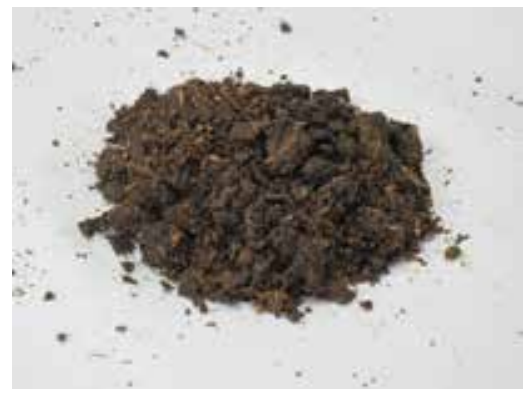

Figure 2. Chicken dung

\subsection{Thermogravimetric Differential Thermal Analysis}

A thermogravimetric differential thermal analysis (TG-DTA) system (RigakuThermoplus TG 8120 Japan) was used to study the overall thermal behaviour of the samples. An open aluminium container $(0.05 \mathrm{ml})$ was used to hold the samples. Figure. 3 shows a schematic diagram of the TG-DTA system. We studied the thermal behaviour of samples of about $20 \mathrm{mg}$ by heating them from room temperature $\left(25^{\circ} \mathrm{C}\right)$ up to $500^{\circ} \mathrm{C}$ at the rate of $2 \mathrm{~K} / \mathrm{min}$ with air circulating at a speed of $150 \mathrm{ml} / \mathrm{min}$.

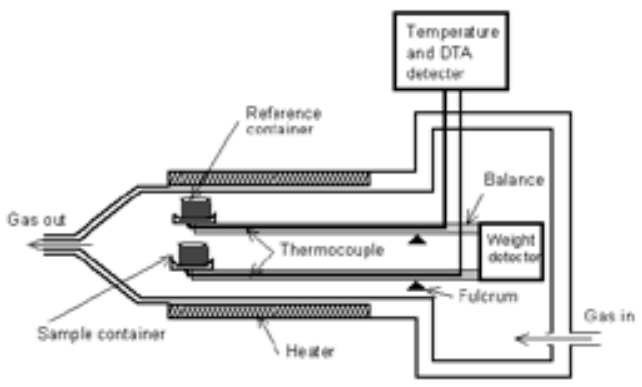

Figure 3. Schematic diagram of the TGDTA system

\subsection{Calorimetry}

A Calvet calorimeter (Setaram C80 France) was used for additional thermal testing. The C80 (Figure. 4) is a twin-type highly sensitive heat-flux calorimeter. It can reduce the effects of vaporization of mo isture contained in a sample by using a high-pressure closed vessel $(8 \mathrm{ml})$ and can take measurements from room temperature $\left(25^{\circ} \mathrm{C}\right)$ up to $100^{\circ} \mathrm{C}$, which is a difficult temperature range to measure using the TG-DTA system. Samples of about $1500 \mathrm{mg}$ were heated from room temperature $\left(25^{\circ} \mathrm{C}\right)$ up to $300^{\circ} \mathrm{C}$ at the rate of $0.1 \mathrm{~K} / \mathrm{min}$.

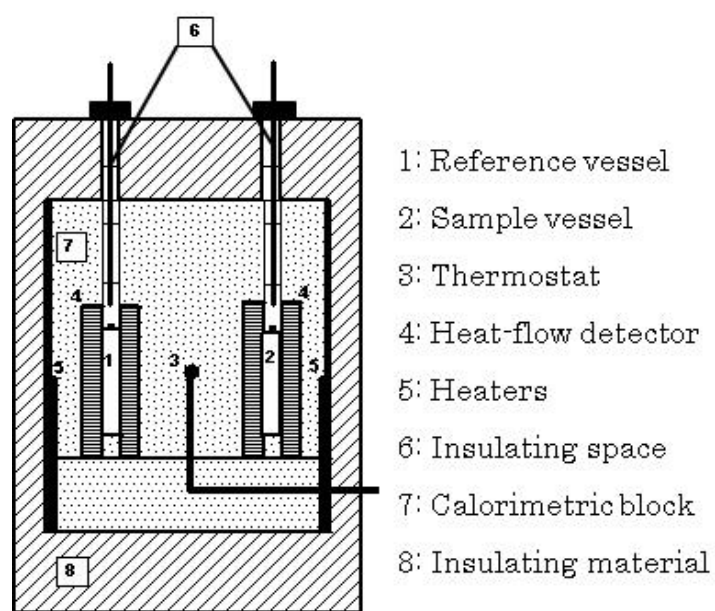

Figure 4. Schematic diagram of the C80

\subsection{Highly Sensitive Isothermal Calorimeter}

To examine the faint heat generation from fermentation in detail, measurements were conducted using a highly sensitive isothermal calorimeter (Thermometric TAM-III Sweden). TAM-III (Figure. 5) can measure the amount of faint heat generated by microbial fermentation at nanoscale. Samples of about $1000 \mathrm{mg}$ were placed in a sealed vessel (4 $\mathrm{ml}$ ) and isothermally maintained at $50^{\circ} \mathrm{C}$ for three days.

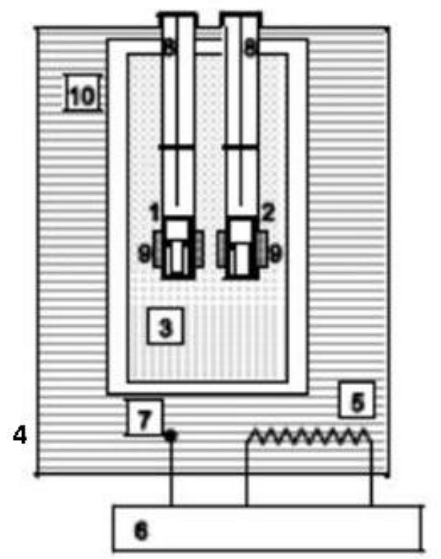
1: Reference vessel
2: Sample vessel
3: Calorimetric block
4: Oil bath
5: Heater
6: Thermostat
7: Temperature sensor
8: Tube introducers
9: Heat flow detectors
10: Heat flow detecting unit

Figure 5. Schematic of T AM-III calorimeter

A summary of the relative sensitivities of the three types of thermal analysis equipment used in this study is shown in Table 2. 
Table 2. Performance and test conditions of the thermal analysis equipmentemployed in this study

\begin{tabular}{|c|c|c|c|c|}
\hline Thermal analysis equipment & $\begin{array}{c}\text { Absolute Sensitivity } \\
(\mathrm{W} / \mathrm{kg})\end{array}$ & $\begin{array}{c}\text { Volume of Vessel } \\
(\mathrm{ml})\end{array}$ & $\begin{array}{c}\text { Measurable } \\
\text { temperature } \\
\text { range }\end{array}$ & Working mode \\
\hline \hline $\begin{array}{c}\text { A thermogravimetric differential } \\
\text { thermal analysis system }\end{array}$ & $3-30$ & 0.05 & $\begin{array}{c}\text { Room temperature } \\
- \\
1000^{\circ} \mathrm{C}\end{array}$ & Heating \\
\hline Calvet calorimeter & $0.005-0.01$ & 8 & Room temperature \\
Highly sensitive isothermal calorimeter & $0.0005-0.001$ & 4 & $\begin{array}{c}\text { Room temperature } \\
-\end{array}$ & Heating \\
Isothermal & & Isothermal \\
\hline
\end{tabular}

\subsection{Gas Chromatography}

To study gas emissions during storage, samples of about $50 \mathrm{~g}$ were placed in $1 \ell$ glass bottles that were sealed airtight and placed in a thermostat oven $\left(25 \pm 5{ }^{\circ} \mathrm{C}\right)$. The gas produced was collected (Figure. 6) and measured by gas chromatography (Shimadzu GC-14B Japan) using standard gas (CO: $0.0500 \%, \mathrm{C}_{2} \mathrm{H}_{6}: 0.995 \%, \mathrm{H}_{2}: 0.097 \%, \mathrm{CO}_{2}$ : $0.996 \%, \mathrm{CH}_{4}: 0.987 \%$ ) for calibration and a thermal conductivity detector (TCD $200{ }^{\circ} \mathrm{C}$, sensitivity $50 \mathrm{~mA}$, carrier gas $\mathrm{Ar}$ at $20 \mathrm{ml} / \mathrm{min})$. The column temperature ranged from $40^{\circ} \mathrm{C}$ (6 min hold) to $80^{\circ} \mathrm{C}$ (12 min hold) to $150^{\circ} \mathrm{C}$ (10 min hold) and changed at the rate of $40^{\circ} \mathrm{C} / \mathrm{min}$.

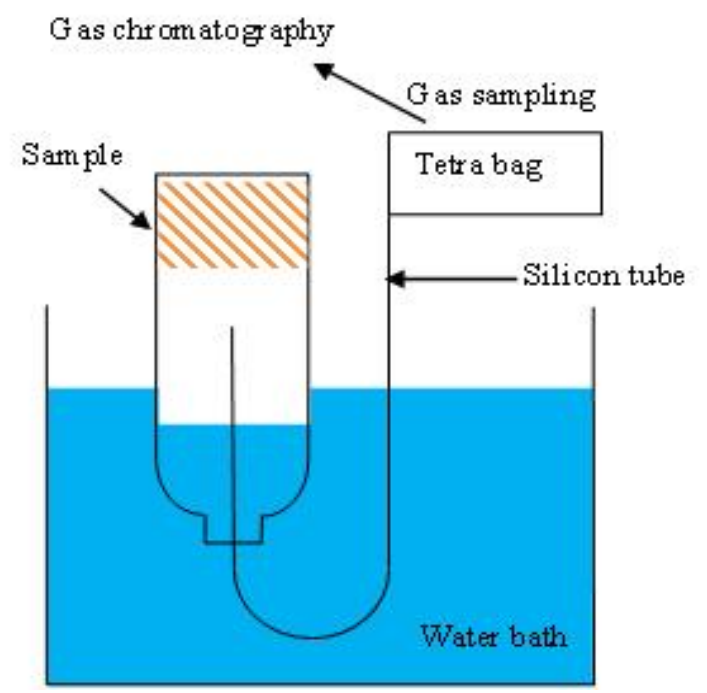

Figure 6. Schematic of gas chromatography measuring device

\section{Results and Discussion}

\subsection{Thermogravimetric Differential Thermal Analysis}

TG-DTA can simultaneously detect changes in mass according to temperature change, decomposition and oxidation, which occur when the sample undergoes thermal change, such as heat generation and heat absorption. Figures 7-11 show the TG-DTA measurement results for a scanning rate of $2 \mathrm{~K} / \mathrm{min}$. Table 3 shows a summary of mass loss at $100^{\circ} \mathrm{C}$ and at the decomposition temperature. The decomposition temperature is that at which the DTA curve shifts by $0.1 \mu \mathrm{V}(0.01 \mathrm{~K})$ from a baseline of constant DTA. The horizontal axis represents the sample temperature and the vertical axis shows the TG (weight change) and DTA (thermal behaviour). The bottom of the TG curve indicates a weight decrease and the top indicates weight increase. For the DTA curve, the downward direction indicates an endothermic reaction and the upward direction indicates an exothermic reaction.

Weight reduction by organic heat decomposition was observed in all the samples in a temperature range from $180^{\circ} \mathrm{C}$ to $380^{\circ} \mathrm{C}$. Above this temperature range, weight reduction and heat generation by carbide combustion were observed. Regarding the unique behaviour observed on the TG curve above $400^{\circ} \mathrm{C}$ for wood pellets (made from the tree trunk) and palm shell, this is assumed to be the result of being outside the increasing temperature rate of $2 \mathrm{~K} / \mathrm{min}$ due to sudden heat generation.

Chicken dung had the lowest temperature at which heat decomposition began at $135.9^{\circ} \mathrm{C}$, and other samples were mostly in between $180^{\circ} \mathrm{C}$ to $200^{\circ} \mathrm{C}$. The possibility that as temperature reaches this range, decomposition and oxidatio $\mathrm{n}$ begins, further raising the temperature, and resulting in ignition, was indicated. The weight reduction rate of chicken dung was highest at $100^{\circ} \mathrm{C}$, and also contained the highest moisture content among the samples. 
Table 3. Mass loss at $100{ }^{\circ} \mathrm{C}$ and at the decomposition temperature

\begin{tabular}{|c|c|c|}
\hline Sample name & $\begin{array}{c}\text { Mass loss } \\
\text { at } 100^{\circ} \mathrm{C}(\%)\end{array}$ & $\begin{array}{c}\text { Decomposition } \\
\text { temperature }\left({ }^{\circ} \mathrm{C}\right)\end{array}$ \\
\hline Wood pellets (made from tree bark) & 10.5 & 188.4 \\
\hline Wood pellets (made from tree trunks) & 8.7 & 198.1 \\
\hline Sludge fuel & 4.4 & 185.6 \\
\hline Chicken dung & 41.4 & 135.9 \\
\hline Palm shell fuel & 9.4 & 181.5 \\
\hline
\end{tabular}

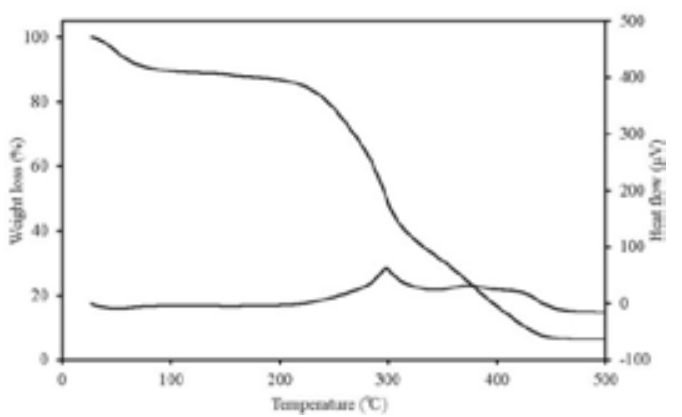

Figure 7. TGDTA results for wood pellets (made from tree bark)

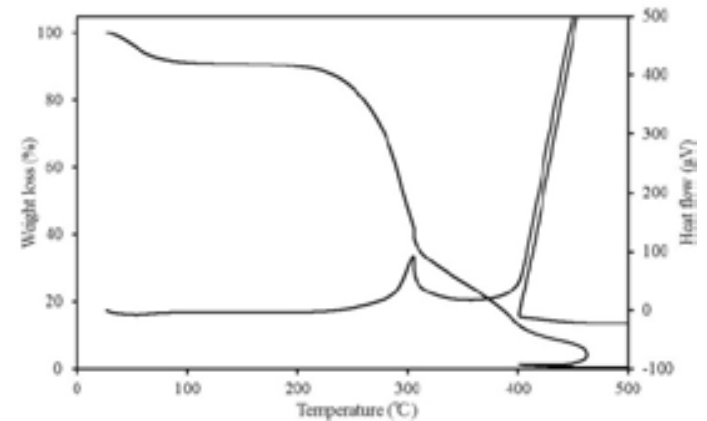

Figure 8. TGDTA results for wood pellets (made from tree trunks)



Figure 9. TGDTA results for sludge fuel



Figure 10. TG-DT A results for chicken dung

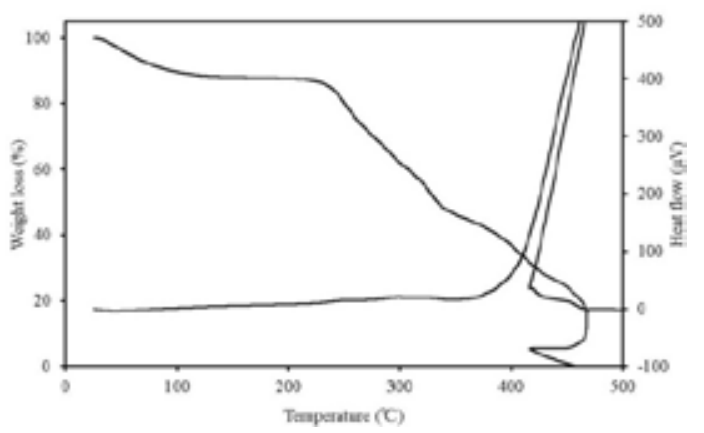

Figure 11. TG-DT A results for palm shell fuel

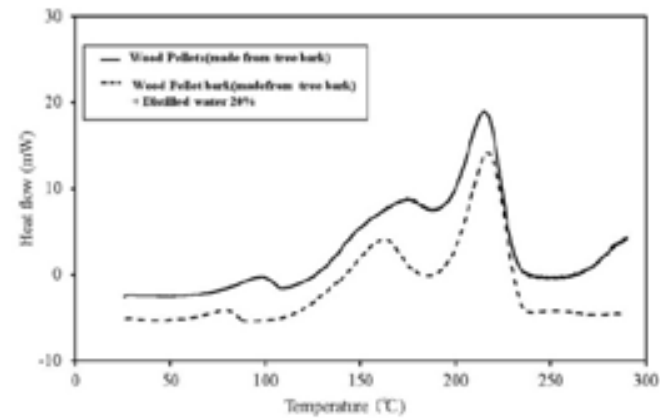

Figure 12. C80 results for wood pellets (made from tree bark)

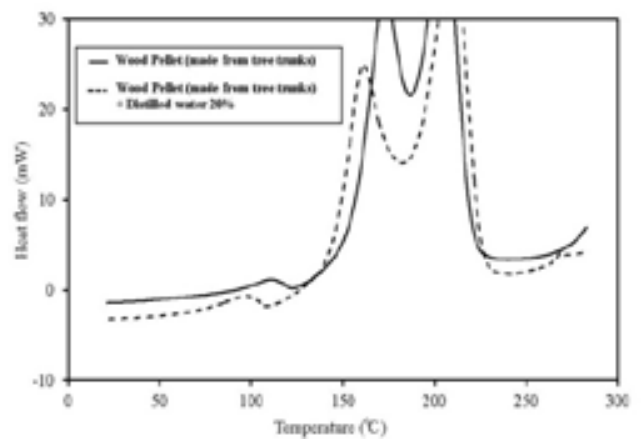

Figure 13. C80 results for wood pellets (made from treetrunks)

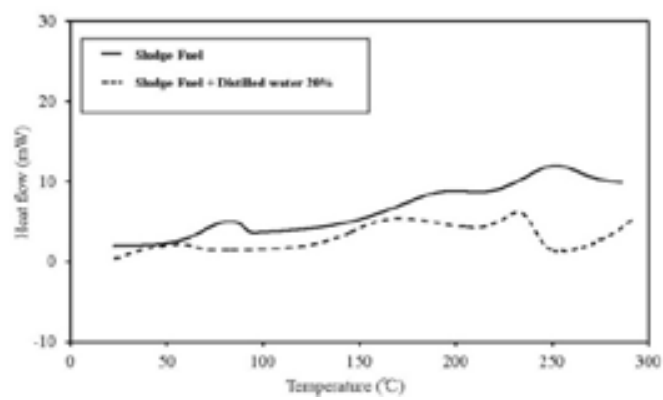

Figure 14. C80 results for sludge fuel 




Figure 15. C80 results for chicken dung

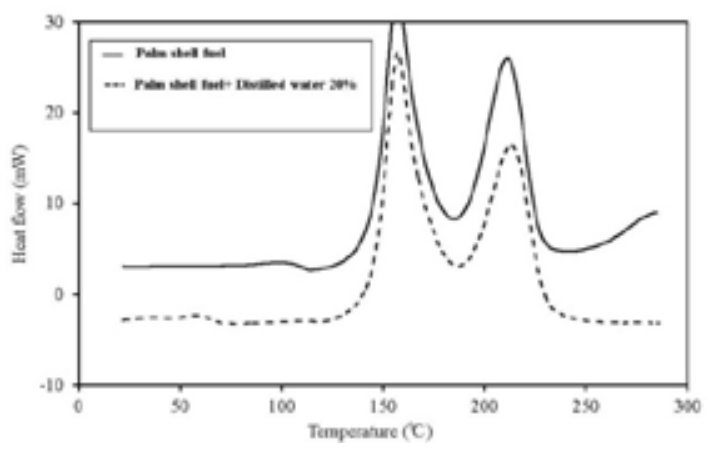

Figure 16. C80 results for palm shell fuel

Most chicken dung is received from poultry houses as is, and is not dry processed. For material to ferment, important factors such as the existence of microorganisms, the appropriate amount of moisture, nutrition source, and oxygen for the microorganisms to propagate, can be mentioned[4]. Chicken dung is more likely to contain many microorganisms and is an appropriate nutrition source for microorganism activity. Moreover, chicken dung is also assumed to more likely ignite than the other samples, because sufficient oxygen is present and it is stored in large amounts. When in a good adiabatic state, temperature increases due to fermentation, and then switches to decomposition and oxidation of the contained organic matter. Furthermore, it has a higher possibility of ignition with an increase in temperature.

\subsection{Calorimetry}

C80 has higher sensitivity than TG-DTA, and the scanning rate can be lowered. Furthermore, a larger amount of the sample can be measured. If a high-pressure, closed vessel is used, the influence of vaporization of the contained mo isture can be reduced. As a result, detailed information on thermal behaviour and the existence of a faint heat generation at temperatures $\leqq 100^{\circ} \mathrm{C}$, which is difficult to obtain by TG-DTA, is possible. Figures 12-16 show the C80 measurement results, where the data was obtained for a scanning rate of $0.1 \mathrm{~K} / \mathrm{min}$.

In addition, the heat generation onset temperature is summarized in Table 4. An experiment was performed in which distilled water was added to the samples (an amount equal to $20 \%$ of the sampleweight ), and the samples were measured to examine the effect of mo isture content on heat generation. When a shift was detected in an exothermic direction after the start ofmeasurement, the temperature at the beginning of the heat generation process was marked as the initial temperature.

When the results were compared, the temperature at which faint heat generation began was lower in all the samples where distilled water was added. Heat generation, which was assumed to be caused by fatty acid esters contained in all samples, was observed over a temperature range of $80^{\circ} \mathrm{C}-100^{\circ} \mathrm{C}$. For temperatures above this range, heat generation assumed to be caused by decomposition was observed. The start of faint heat generation after adding moisture, assumed to be caused by fermentation, was observed in sludge fuel and chicken dung immediately after measurements began. Sludge fuel and chicken dung are more likely to generate heat, even at temperatures $30^{\circ} \mathrm{C}$ or less.

On the basis of the C80 results, it is desirable to incorpor ate the following safety measures: first, if the internal temperature of the biomass fuel is between $30^{\circ} \mathrm{C}$ and $50^{\circ} \mathrm{C}$, fermentation begins and only faint heat is generated from fermentation and breaking down the pile. Conducting a heat dissipation treatment at this stage lowers the possibility of a further increase in temperature that could lead tospontaneou $s$ ignition. Second, if the internal temperature of the biomass fuel is between $50^{\circ} \mathrm{C}$ and $80^{\circ} \mathrm{C}$, fermentation as well as oxidation of the fatty acid esters produced by fermentation occurs. Self-heating is already in progress at this stage and immediate treatment is required. At this stage, breaking down the pile increases the oxygen supply to the area of self-heating, rapidly increasing the temperature and the possibility of combustion. The amount of heat generated by these reactions is larger than that caused by fermentation. Venting inactive gas and spraying with water as needed at this stage is recommended.

Table 4. Results of C80 (Heat generation onset temperature)

\begin{tabular}{|c|c|}
\hline Sample names & $\begin{array}{c}\text { Heat generation } \\
\text { onset temperature }\left({ }^{\circ} \mathrm{C}\right)\end{array}$ \\
\hline \hline $\begin{array}{c}\text { Wood pellets (made from tree bark) } \\
\text { +Distilled water 20\% }\end{array}$ & 59.3 \\
\hline $\begin{array}{c}\text { Wood pellets (made from tree bark) } \\
\text { Wood pellets (made from tree trunks) }\end{array}$ & 48.3 \\
\hline $\begin{array}{c}\text { Wood pellets (made from tree trunks) } \\
\text { +Distilled water 20\% }\end{array}$ & 64.3 \\
\hline Sludge fuel & 56.2 \\
\hline $\begin{array}{c}\text { Sludge fuel } \\
\text { +Distilled water 20\% }\end{array}$ & 42.1 \\
\hline Chicken dung & 26.3 \\
\hline $\begin{array}{c}\text { Chicken dung } \\
\text { +Distilled water 20\% }\end{array}$ & 28.5 \\
\hline $\begin{array}{c}\text { Palm shell fuel } \\
\text { Palm shell fuel } \\
\text { +Distilled water 20\% }\end{array}$ & 26.1 \\
\hline
\end{tabular}




\subsection{Highly Sensitive Isothermal Calorimeter}

TAM-III can measure the change in the activity of microorganis $m$ with time. Figures 17-21 show the TAM-III results. Table 5 summarizes the amount of heat generated. Heat generation is divided into two periods and has been considered for 0-24 h, 24-72 h and for a combination of both the time periods. An experiment was performed in which distilled water was added to the samples (an amount equal to $20 \%$ of the sample weight), and the samples were measured to examine the effect of mo isture content on heat generation. The TAM-III temperature was held at $50^{\circ} \mathrm{C}$ for all tests, because microbial actively occurs most vigorously in this temperature range but becomes inactive at higher temperatures [5-6].

Considering the thermal behaviour of wood pellets (made from tree bark), when distilled water was added and then measured, heat generation started immediately after measurement began and increased again after $24 \mathrm{~h}$. This is assumed to occur because microorganisms become more active over a period of time. Then, as oxygen in the sealed sample container is consumed by rapid fermentation, the reaction begins to become inactive.

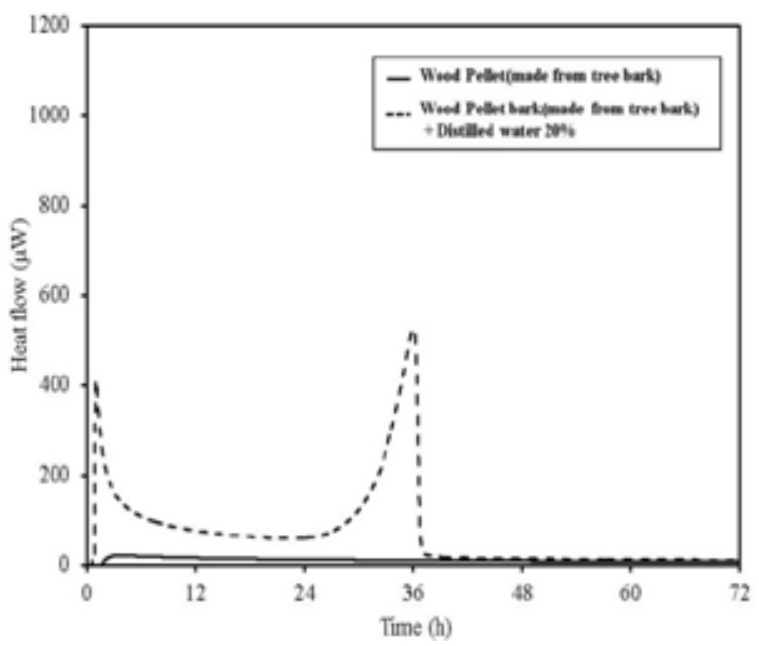

Figure 17. TAM-III results for wood pellets (made from tree bark)

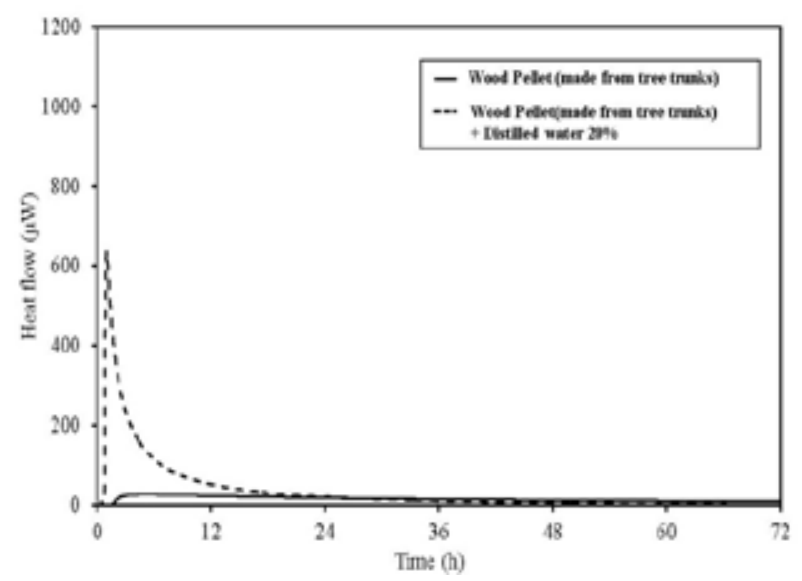

Figure 18. TAM-III results for wood pellets (made from treetrunks)

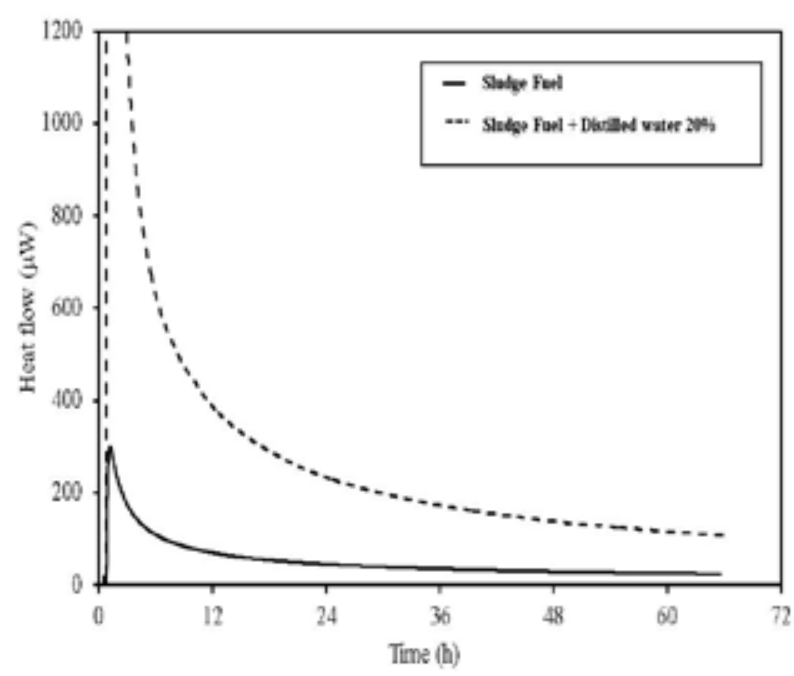

Figure 19. TAM-III results for sludge fuel



Figure 20. TAM-III results for chicken dung

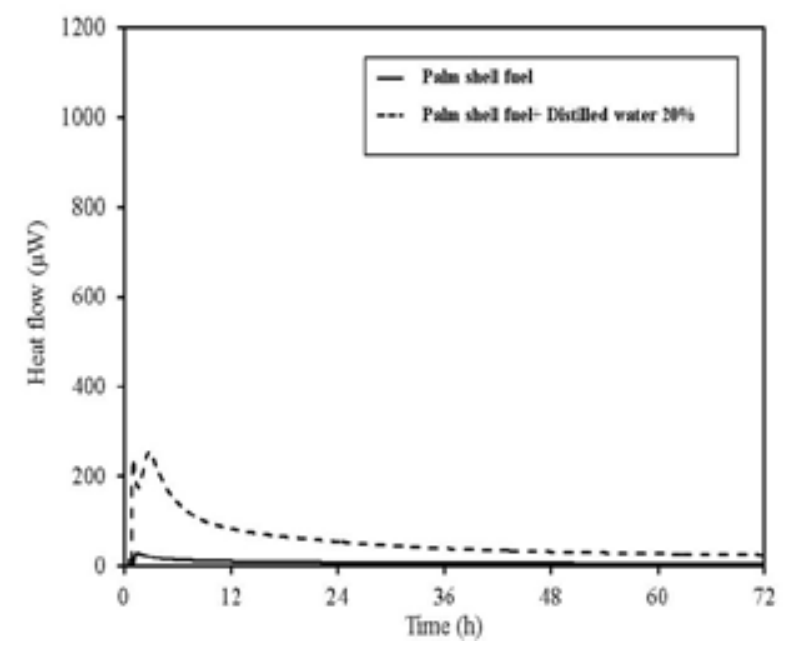

Figure 21. TAM-III results for palm shell fuel 
Table 5. Heat generation at $50^{\circ} \mathrm{C}$

\begin{tabular}{|c|c|c|c|}
\hline Sample names & $\begin{array}{l}\text { Heat generation }(\mathrm{J} / \mathrm{g}) \\
0-24 \mathrm{~h}\end{array}$ & $\begin{array}{c}\text { Heat generation }(\mathrm{J} / \mathrm{g}) \\
24-72 \mathrm{~h}\end{array}$ & $\begin{array}{l}\text { Heat generation }(\mathrm{J} / \mathrm{g}) \\
0-72 \mathrm{~h}\end{array}$ \\
\hline Wood pellets (made from tree bark) & 1.3 & 1.6 & 2.9 \\
\hline $\begin{array}{l}\text { Wood pellets (made from tree bark) } \\
\text { +Distilled water } 20 \%\end{array}$ & 7.9 & 10.4 & 18.3 \\
\hline Wood pellets (made from tree trunks) & 1.7 & 2.0 & 3.7 \\
\hline $\begin{array}{l}\text { Wood pellets (made from tree trunks) } \\
+ \text { +Distilled water } 20 \%\end{array}$ & 10.1 & 2.9 & 13.0 \\
\hline Sludge fuel & 17.7 & $11.1^{*}$ & $28.9 * *$ \\
\hline $\begin{array}{c}\text { Sludge fuel } \\
+ \text { Distilled water } 20 \%\end{array}$ & 35.1 & $8.5^{*}$ & $43.6 * *$ \\
\hline Chicken dung & 3.7 & 5.7 & 9.4 \\
\hline $\begin{array}{c}\text { Chicken dung } \\
\text { +Distilled water } 20 \% \\
\end{array}$ & 80.4 & $96.8^{*}$ & $177.2^{* *}$ \\
\hline Palm shell fuel & 1.1 & 1.0 & 2.1 \\
\hline $\begin{array}{c}\text { Palm shell fuel } \\
\text { +Distilled water } 20 \%\end{array}$ & 9.0 & 6.1 & 15.1 \\
\hline
\end{tabular}

*24-64 h **0-64 h

Table 6. GC results for the biomass fuels used in this study

\begin{tabular}{|c|c|c|c|c|c|c|}
\hline \multirow{2}{*}{ Sample names } & \multirow{2}{*}{$\begin{array}{l}\text { Storage } \\
\text { period }\end{array}$} & \multirow{2}{*}{$\begin{array}{l}\text { Storage } \\
\text { temperature }\end{array}$} & \multicolumn{4}{|c|}{ GC analysis resaults (\%) } \\
\hline & & & $\mathrm{H}_{2}$ & $\mathrm{CO}$ & $\mathrm{CH}_{4}$ & $\mathrm{CO}_{2}$ \\
\hline Wood pellets (made from tree bark) & \multirow{10}{*}{10 days } & \multirow{10}{*}{$25^{\circ} \mathrm{C}$} & 0.001 & - & - & 0.7 \\
\hline $\begin{array}{l}\text { Wood pellets (made from tree bark) } \\
\text { +Distilled water } 20 \%\end{array}$ & & & 0.014 & - & - & 21.7 \\
\hline Wood pellets (made from tree trunks) & & & 0.002 & - & - & 0.08 \\
\hline $\begin{array}{c}\text { Wood pellets (made from tree trunks) } \\
+ \text { +Distilled water } 20 \%\end{array}$ & & & 0.005 & - & - & 1.9 \\
\hline Sludge fuel & & & - & - & - & 0.5 \\
\hline $\begin{array}{c}\text { Sludge fuel } \\
+ \text { Distilled water } 20 \%\end{array}$ & & & - & - & - & 2.3 \\
\hline Chicken dung & & & - & - & - & 14.2 \\
\hline $\begin{array}{c}\text { Chicken dung } \\
\text { +Distilled water } 20 \%\end{array}$ & & & 0.273 & - & - & 22.0 \\
\hline Palm shell fuel & & & - & - & - & 0.06 \\
\hline $\begin{array}{c}\text { Palm shell fuel } \\
\text { +Distilled water } 20 \%\end{array}$ & & & - & - & - & 3.1 \\
\hline
\end{tabular}

In wood pellets (made from tree trunks), similar to those made from tree bark, an increase in heat generation was observed when distilled water was added. However, heat generation in two phases, such as that which occurred for the wood pellets made from the bark was not observed. Furthermore, in sludge fuel, chicken dung and palm shell 
fuel, an increase in heat generation was observed associated with the addition of distilled water. The amount of heat generated by chicken dung was approximately 19 times when distilled water was added. Sludge fuel and chicken dung are made from the sludge and waste and are more likely to contain a large number of microorganisms, which are assumed to become active with the addition of distilled water.

Water is normally useful for fire extinguishing and prevention, but for biomass fuels made from waste the existence of an appropriate amount of moisture promotes the possibility of fermentation. As it is easier to generate heat, the risk of spontaneous ignition is also considered to increase.

\subsection{Gas Chromatography}

Regarding one risk related to the storage location, confirmation of the release of flammable gases such as hydrogen, methane and carbon monoxide is important. There have been cases in which waste in a waste disposer has fermented, filling the place with flammable gases and causing an explosion[7], as well as cases in which active fermentation occurred in a storage location and a large amount of carbon dio xide was released, resulting in death of workers due to lack of oxygen[6].

Results of the GC analysis are shown in Table 6. When the results are compared, it is obvious that there was an increase in the amount of carbon dioxide generated in all samples when distilled water was added. Regarding the generation of hydrogen, there is a high possibility of anaerobic fermentation in addition to aerobic fermentation. According to the measurement conditions at this time, no carbon monoxide or methane was detected. In wood pellets (made from tree bark), a large increase in carbon dioxide was observed with the addition of moisture. In chicken dung, high generation of carbon dioxide was observed both when distilled water was added and when it was not. Considering its thermal behaviour, chicken dung is assumed to contain more moisture and believed to be conducive to fermentation. Other samples contain about $10 \%$ mo isture and may also contain microorganisms, but these samples do not have enough moisture for microorganis ms to become active, so fermentation is assumed to be difficult under normal conditions.

However, when the amount of contained mo isture is increased by some factor, fermentation is assumed to occur, leading to temperature increase and spontaneous ignition. Under normal conditions, even if flammable gas and carbon dioxide are released, they are diffused in the air and their concentration decreases, so the risk from these gases is lower. However, when biomass fuel that is likely to ferment is transported in a tightly sealed container or stored for a long period of time in a silo, caution is required to avoid ignition and explosion. Measuring generated gas using a gas detection tube, in addition to temperature monitoring and regular confirmation of whether fermentation is occurring or flammab le gases are being generated, is recommended.

\subsection{Risk ranking of Biomass Fuels}

No clear risk assessment method for biomass fuels has been established in Japan. An early establishment of an effective and quick method to determine the risk is desired. From the measurement results in this study, a relative assessment method combining thermal and gas analysis equipment was evaluated by considering the temperature at which heat generation began, the amount of heat generated and the amount of flammable gas generated as indicators.

The temperature at which heat was generated was a conductive temperature for heat reaction and the amount of heat generated indicated the extent of heat generation. The temperature at which heat generation began was determined by targeting the temperature at which minute heat generatio $n$ began, using the results of C80 (Table 3). In order to compare the risk according to the temperature at which heat was generated in each sample, the score was set based on the following standard. The higher the score, the greater the possibility of heat generating at a lower temperature and greater the risk involved.

The score of the temperature at which heat generation began was set according the results of $\mathrm{C} 80$ (see Table 4).

$$
\begin{aligned}
& 0{ }^{\circ} \mathrm{C} \leqq(5)<30^{\circ} \mathrm{C} \leqq(4)<60^{\circ} \mathrm{C} \leqq \\
& \text { (3) }<90^{\circ} \mathrm{C} \leqq(2)<120^{\circ} \mathrm{C} \leqq(1)<150^{\circ} \mathrm{C}
\end{aligned}
$$

The total amount of heat generation right after measurement began by $\mathrm{TAM}$ at $50^{\circ} \mathrm{C}$ and up to 72 hours later, was used as the amount of heat generation. In order to compare the risk which amount of heat generation in each sample, the score was set based on the following standard. The higher the score, the greater the amount of heat generation was and the greater the risk.

The score of the amount of heat generation was set based on the results of TAM (see Table 5).

$$
\begin{aligned}
& 0 \mathrm{~J} / \mathrm{g} \leqq(1)<10 \mathrm{~J} / \mathrm{g} \leqq \text { (2) }<20 \mathrm{~J} / \mathrm{g} \leqq \text { (3) }<30 \mathrm{~J} / \mathrm{g} \leqq \\
& \text { (4) }<40 \mathrm{~J} / \mathrm{g} \leqq \text { (5) }<50 \mathrm{~J} / \mathrm{g} \leqq \text { (6) }<60 \mathrm{~J} / \mathrm{g}
\end{aligned}
$$

Risk for flammable gases is derived directly from their concentration. Consider a mixture of flammable gases and air in which the percentages of flammable gases with their respective limits of $\mathrm{N}, \mathrm{N}$ ', N'... are $\mathrm{n}, \mathrm{n}$ ', n',... Le Chatelier[8-9]proposed the following rule: the flammability limit of the complex mixture occurs at percentages $n, n^{\prime}$ and $\mathrm{n}^{\prime \prime}$ such that

$$
\frac{n}{N}+\frac{n^{\prime}}{N^{\prime}}+\frac{n^{\prime \prime}}{N^{\prime \prime}}+\cdots=1
$$

He justified the rule in the following way: it is more or less obvious that if two mixtures $\left(\mathrm{G}+\right.$ air) and $\left(\mathrm{G}^{\prime}+\right.$ air) combine to form a homogeneous mixture, then the latter will propagate a flame if both initial mixtures support propagation, and it will not propagate a flame if both initial mixtu res are either below the lower limit or above the upper limit, resulting in a mixture in which $G$ and $G^{\prime}$ are present in percentages $\mathrm{n}$ and $\mathrm{n}^{\prime}$, such that

$$
\frac{n}{N}+\frac{n^{\prime}}{N^{\prime}}=1
$$


is at the propagation limit ( lower or upper depending on whether $\mathrm{N}$ and $\mathrm{N}^{\prime}$ are relative to the individual lower or upper limits). The argument can be easily extended to other gases, and leads to formula (3).

Risk of flammable gases generation is therefore done by combining the concentrations of all evolved flammable gases such as $\mathrm{H}_{2}, \mathrm{CO}, \mathrm{CH}_{4}$, generation which are detected by the GC and comparing with their lower explosion limit, which is $4.0 \%$ for $\mathrm{H}_{2}, 12.5 \%$ for $\mathrm{CO}, 5.0 \%$ for $\mathrm{CH}_{4}$. In order to compare the risk which flammable gas generation in each sample, the score was set based on the following standard.This calculation is excludes the effect of $\mathrm{CO}_{2}$. Rank of flammable gases evolution $=\frac{\left[\mathrm{H}_{2}\right]}{4.0 \%}+\frac{[\mathrm{CO}]}{12.5 \%}+\frac{\left[\mathrm{CH}_{4}\right]}{5.0 \%}(5)$

The score of the flammable gases generation was set according the results of GC (see Table 6)

$$
\begin{aligned}
& 0 \% \leqq(1)<0.001 \% \leqq(2)<0.01 \% \leqq \\
& \text { (3) }<0.1 \% \leqq(4)<1 \% \leqq(5)<10 \%
\end{aligned}
$$

A summary of the relative risk of the biomass fuels used at this time, using the prescribed assessment method, is shown in Table 7. Moreover, a summary of the results based on the table is shown in Figures. 22-23.The horizontal axis in the graph shows the risk according to the temperature at which heat generation began, calculated from the value of $\mathrm{C} 80$, and the vertical axis shows the risk according to the amount of heat generated calculated from the value of the TAM-III. The size of the circle indicates the risk of generation of flammable gas calculated from the value of GC measurements. Points that plot higher on the right have higher thermal risk. Moreover, a larger circle indicates a higher risk of generating fla mmable gas.

When the results are compared for the biomass fuels measured at this time, the risk of at least one of the following heat generation temperature, heat generation amount or flammable gas generation increases as a result of the addition of distilled water. When viewed comprehensively, there is a possibility that chicken dung and sludge fuel may generate heat even at $30^{\circ} \mathrm{C}$ or less and that the amount of heat generated when distilled water is added also increases the risk of generating flammable gases. For other samples, the temperature at which heat generation occurs was lowered by adding distilled water, but the amount of heat generated and the risk of flammable gas was not lowered to the same extent as in chicken dung and sludge fuel. Other samples are assumed to be more stable than chicken dung and sludge fuel.

This method is assumed to be effective in confirming heat generation that can trigger of spontaneous ignition and in determining the risk posed by newly developed biomass fuels. Sensitive thermal and gas analysis equipment is first used to determine whether minute heat or flammable gas, which may trigger of spontaneous ignition, are generated. Next, for samples with higher risk, the possibility of an increase in temperature by minute heat generation occurring under more adiabatic conditions is considered. Moreover, for samples with a higher possibility of retaining increased temperature, the amount of sample can be increased and the results studied more closely. Then, an estimation of the ignition temperature in a large scale condition can be performed according to the data obtained by a theoretical method such as the Frank-Kamenetskii[10] method. For the risk assessment method, thermal and gas analysis equipment were used, but depending on the combination of equipment and data it may be possible to use this method in consideration of the effectiveness of biomass products as fuel.

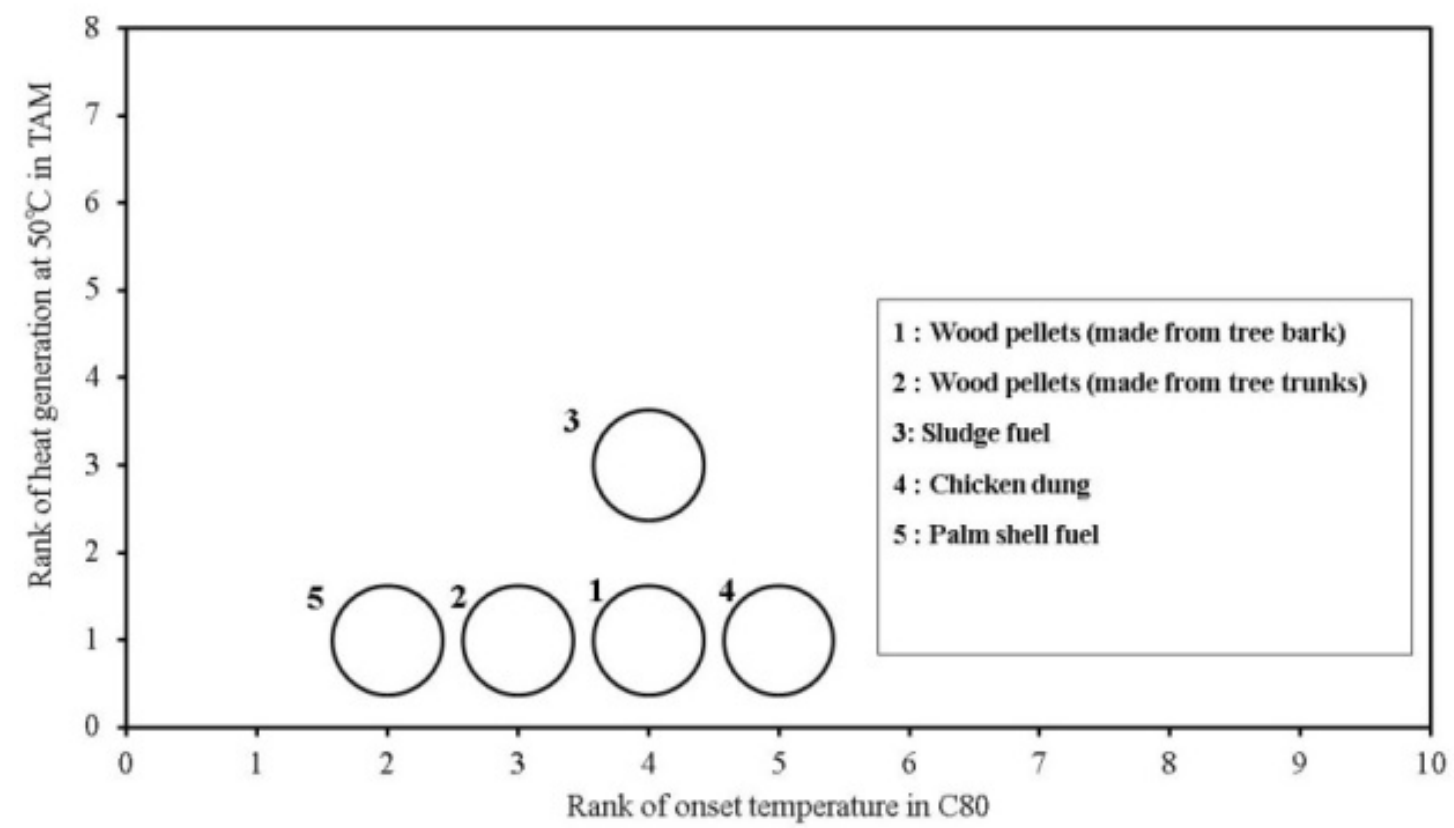

Figure 22. Overall comparison of risks for onset temperat ure and heat generation and flammable gas generation of biomass fuels used in this study 


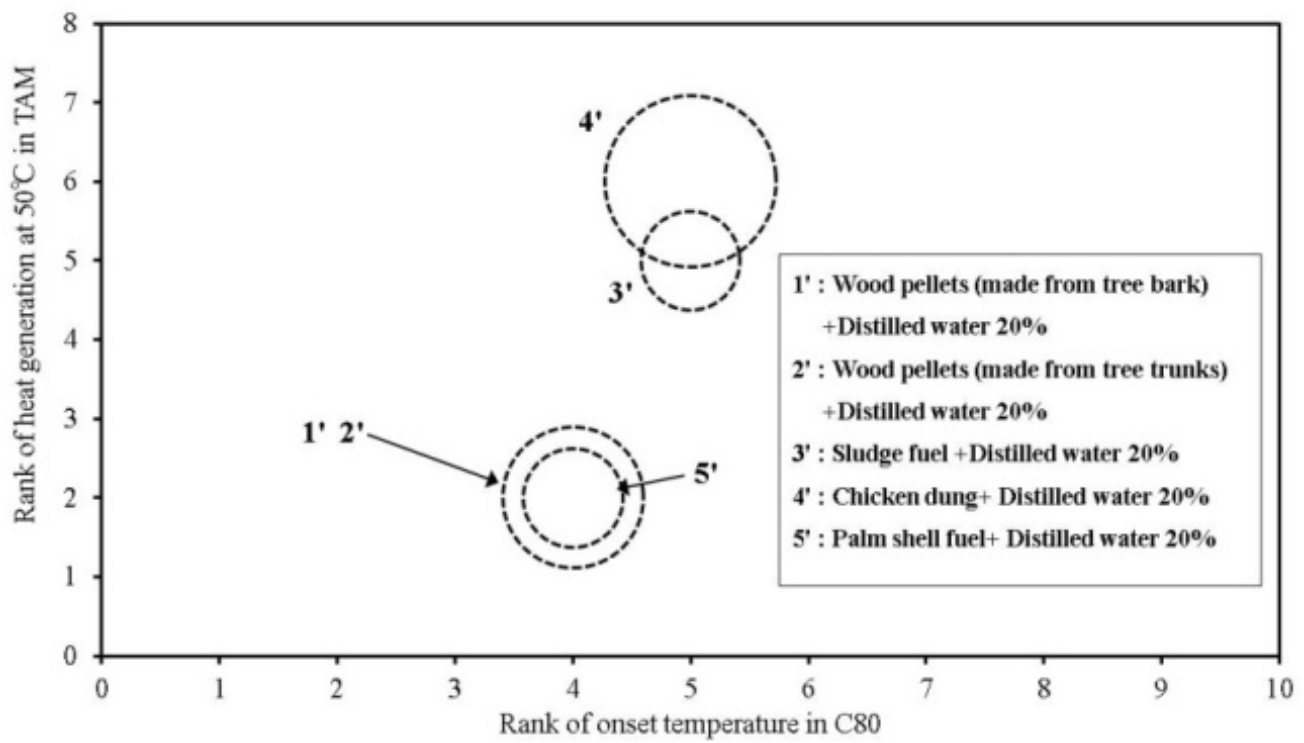

Figure 23. Overall comparison of risks for onset temperat ure and heat generation and flammable gas generation of biomass fuels used in this study (add to distilled water)

Table 7. Risk ranking of the biomass fuels used in this study

\begin{tabular}{|c|c|c|c|}
\hline \multirow{2}{*}{ Sample name } & \multicolumn{2}{|c|}{ Thermal risk } & Flammable gas risk \\
\cline { 2 - 4 } & $\mathrm{T}_{\text {onset }}(\mathrm{C} 80)$ & $\mathrm{Q}$ (TAM) & $25 \pm 5{ }^{\circ} \mathrm{C}(\mathrm{GC})$ \\
\hline Wood pellets (made from tree bark) & 4 & 1 & 1 \\
\hline $\begin{array}{c}\text { Wood pellets (made from tree bark) } \\
\text { +Distilled water 20\% }\end{array}$ & 4 & 2 & 2 \\
\hline $\begin{array}{c}\text { Wood pellets (made from tree trunks) } \\
\text { Wood pellets (made from tree trunks) } \\
\text { +Distilled water 20\% }\end{array}$ & 3 & 2 & 2 \\
\hline Sludge fuel & 4 & 3 & 1 \\
\hline $\begin{array}{c}\text { Sludge fuel } \\
\text { +Distilled water 20\% }\end{array}$ & 5 & 5 & 1 \\
\hline Chicken dung & 5 & 1 & 1 \\
\hline $\begin{array}{c}\text { Chicken dung } \\
\text { +Distilled water 20\% }\end{array}$ & 5 & 6 & 1 \\
\hline Palm shell fuel & 4 & 2 & 1 \\
\hline $\begin{array}{c}\text { Palm shell fuel } \\
\text { +Distilled water 20\% }\end{array}$ & 5 & & 2 \\
\hline
\end{tabular}

\section{Conclusions}

Based on the experimental results, the following conclusi ons were obtained.

(1) Based on the results of the TG-DTA system measurements, chicken dung had the lowest temperature at which heat decomposition began $\left(135.9^{\circ} \mathrm{C}\right)$, and for other samples it was mostly in the range of $180^{\circ} \mathrm{C}$ to $200^{\circ} \mathrm{C}$. It is possible that as the temperature reaches this range, decomposition and oxidation begins, further raising the temperature and resulting in the ignition.

(2) Based on the results of C80, the temperature at which heat generation began was low in all samples when distilled water was added before the measurement. The start of heat generation under these conditions, assumed to be caused by fermentation, was observed in sludge fuel and chicken dung immediately after measurements began. Sludge fuel and chicken dung are more likely to generate heat, even at 
temperatures of $30^{\circ} \mathrm{C}$ or less.

(3) If the internal temperature of the stored biomass fuel is between $30^{\circ} \mathrm{C}$ and $50^{\circ} \mathrm{C}$, fermentation begins and only a small amount of heat is generated from fermentation and breaking down the pile. If the internal temperature of the stored biomass fuel is between $50{ }^{\circ} \mathrm{C}$ and $80{ }^{\circ} \mathrm{C}$, fermentation and oxidation of the fatty acid esters produced by fermentation occurs. Self-heating is already in progress at this stage and immediate treatment is required.

(4) As shown in the results of the TAM-III measurements, all samples generated a greater amount of heat as a consequence of increased moisture content. This micro-heat generation is the trigger of fires. And it is believed that moderate moisture content in an item enables better fermentation and generates heat more easily. Sludge fuel and chicken dung, composed of sludge and waste respectively, are more likely to contain a large amount of microorganis ms, which are assumed to become active with the addition of distilled water.

(5) As shown in the results of the GC measurements, there was an increase in the amount of carbon dioxide generated in all samples when distilled water was added. Under normal conditions, even if flammable gas and carbon dioxide are released, they are diffused in the air and their concentration decreases, so the risk from these gases is low. However, when biomass fuel that is likely to ferment is transported in a tightly sealed container or stored for a long period of time in a silo, caution is required to avoid ignition and explosion.

(6) As shown in the results of the risk ranking method for the biomass fuels measured at this time, the risk of at least one of heat generation temperature, heat generation amount and flammable gas generation is increased as a result of the addition of distilled water. There is a possibility that chicken dung and sludge fuel may generate heat even at $30^{\circ} \mathrm{C}$ or less and that the amount of heat generated when distilled water is added also increases the risk of generating flammable gases. For other samples, the temperature at which heat generation began was lowered by adding distilled water, but the amount of heat generated and the risk of flammable gas was not lowered to the same extent as for chicken dung and sludge fuel.

\section{REFERENCES}

[1] H, Koseki. (2011) Evaluation of Various Solid Biomass Fuels Using Thermal Analysis and Gas Emission Tests, Energies, 4: 616-627.

[2] The United Nations (2003) Recommendations on the Transport of Dangerous Goods, Manual of Tests and Criteria, Fourth revised edition.

[3] X.R, Li., H, Koseki, Y, Iwata. and W-S, Lim. (2008) Thermal behaviour of sewage sludge derived fuels, Thermal Science, 12(2): 137-148.

[4] Z.M., Fu., X.R, Li. and H, Koseki. (2005) Heat generation of refuse derived fuel with water, Journal of Loss Prevention in the Process Industries, 18: 27-33.

[5] X.R, Li., H, Koseki. and M, Momota. (2006) Evaluation of danger from fermentation-induced spontaneous ignition of wood chips, Journal of Hazardous Materials, 135(1-3): 15-20.

[6] N, Murasawa., H, Koseki.,Y, Iwata., Y,Shibata. (2012) Determination of Spontaneous Ignition of SSSR and Fish meal during Transport and Storage, Journal of Food Research 1:320-329.

[7] X.R, Li., H, Koseki. and Y, Iwata. (2008) Risk Assessment on Processing Facility of Raw Organic Garbage, Journal of Hazardous Materials, 154(1-3): 38-43.

[8] H. Le Chatelier.(1891) Estimation of firedamp by flammability limits, Annals of Mines, 19 (8) 388-395.

[9] L.A. Medrard(1987) Accidental explosions, Volume 1: physical and chemical properties,Flammability limits of explosive gaseous mixtures, 163-173

[10] D.A Frank-Kamenetskii.(1969) Diffusion and Heat Transfer in Chemical kinetics, 374. 